\title{
Tarnish and Corrosion Behaviour of Dental Gold Alloys
}

\author{
Leon W. Laub* and John W. Stanford** \\ *Loyola University School of Dentistry, Maywood, IL., U.S.A. \\ **American Dental Association, Chicago, IL., U.S.A.
}

\begin{abstract}
For many years the specification of alloy composition, particularly high gold and platinum contents, was considered sufficient to guarantee the stability of dental prostheses in the oral environment. This article reveals a considerably more complex situation and stresses the need for extensive laboratory and clinical testing of new alloy formulations before these may be unreservedly recommended to practitioners.
\end{abstract}

In the 1940's, dental gold alloys containing more than 75 per cent gold and platinum group metals (PGM's) were considered tarnish-resistant, whereas alloys of lower noble metal contents were not thought to have acceptable tarnish resistance, especially in the presence of sulphide vapours (1). When the current standard for the composition and physical properties of dental casting gold alloys became effective in 1966 as 'American National Standards Institute/ American Dental Association (ADA) Specification No. 5 for Dental Casting Gold Alloys' (2) (also adopted as 'Féderation Dentaire Internationale Specification No. $7^{\prime}$ ), the composition requirements were thought to assure alloys which had good tarnish and corrosion resistance in the oral environment. In these specifications, alloys are classified according to their minimum contents of gold + PGM: 83 per cent by weight for Type I, 78 per cent for Type II (Vickers Hardness Number in the quenched condition 90 to 120 ) and Type III (Vickers Hardness Number in the quenched condition 120 to 150 ), and 75 per cent for Type IV. However, there have been occasional reports of tarnish in clinical restorations (3). Recent laboratory studies have confirmed that composition requirements alone are not sufficient to assure corrosion resistance (4).

Partly in response to the cost of noble metals, manufacturers of dental alloys have developed a large number of alternative casting alloys having lower noble metal contents than those specified in (2). Thus, many dental laboratories are using low gold content alloys for inlays (5). A recent survey of the U.S. market (6) revealed the availability of commercial gold alloys containing from 15 to 72 per cent gold, with an average of 53 per cent, and a minimum gold + PGM content of 33 per cent. The corrosion resistance of these alloys may vary widely. In addition to the requirement of good resistance to tarnish and corrosion, the selection of a low gold content alloy for use as a crown and bridge material depends on its physical and mechanical properties and its biocompatibility. The more important characteristics are castability (including reproduction of fine details), fit of the restoration, sufficient hardness to withstand the forces developed in mastication, sufficient elongation to permit burnishing, ease of soldering and tolerance by mouth tissues. Acceptable characteristics have been reported for several low gold content alloys with regard to castability $(7,8)$, fit $(9,10,11)$, hardness $(10,12)$ and burnishability $(7,10,11)$. Until a specification is developed for such alloys, they may be classified in the 'Acceptance Program for Alloys for Cast Dental Restorative Prosthetic Devices' of the Council of Dental Materials, Instruments and Equipment of the ADA (13). The guidelines of this program suggest that results of corrosion testing be submitted in support of product claims, but does not specify test methods. Currently, a Technical Committee of the International Organization for Standardization (ISO/TC106) is considering the adoption of particular corrosion test methods for dental casting alloys.

The objectives of this review are to:

(1) Describe laboratory test methods which have been used to evaluate tarnish and corrosion of dental gold alloys

(2) Relate results from laboratory tests to the available clinical (in vivo) studies of corrosion

(3) Compare the corrosion behaviour of low gold content alloys with that of traditional gold-rich dental alloys.

\section{Tarnish}

Tarnish is defined as a surface discolouration or decrease in lustre of an alloy restoration which may be due to the formation of a surface product. Long term 
alloy immersion in a solution which simulates mouth conditions provides the surest in vitro procedure to predict clinical behaviour of the alloy. However, accelerated immersion tests are preferred by alloy developers and by investigators for testing compliance with specifications, but such tests must be proven to predict long term and ultimately, clinical behaviour.

Several synthetic saliva solutions, as well as aggressive solutions have been used in attempts to identify in accelerated tests the conditions under which an alloy tarnishes. Since chlorides are present in saliva and certain foods such as fish and eggs have a high sulphur content, both chloride and sulphide solutions are commonly chosen as immersion test media.

Dental alloys have thus been subjected to immersion tests in various sulphide, chloride, and artificial saliva solutions. Tarnishing occurs primarily in sulphide solutions and the tarnish has been identified as a sulphide of silver. Ranking of alloys in terms of susceptibility to such tarnishing has been recorded both subjectively, by comparing colour changes visually with a pre-established scale of colour variation, and quantitatively, using a colorimeter or spectrophotometer, Specific test methods are described below.

In one of the early studies (14), a Type II alloy and a gold solder (containing 49 per cent gold by weight) were immersed in several sodium chloride and sodium sulphide solutions for 66 days. No tarnish was observed on the gold-rich Type II alloy, but the gold solder discoloured slightly in the sulphide solutions after 18 days. These results corroborated the thinking of the time, namely that sulphide tarnish affects only low gold content alloys. However, dentists occasionally reported gold-rich alloy restorations

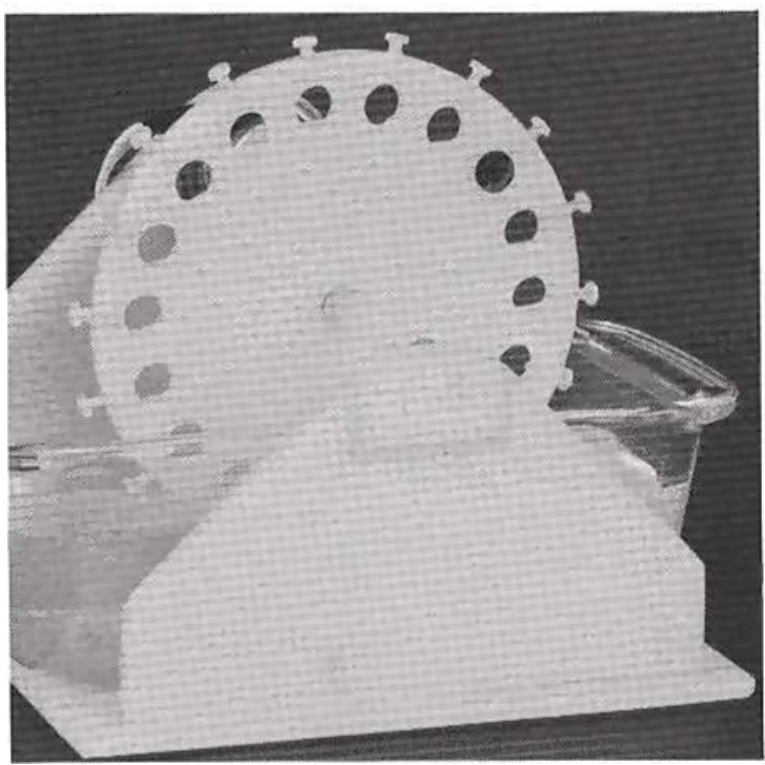

which tarnished in the oral environment. Electron probe analyses of several such restorations indicated that the tarnish product was a sulphide mixed with a carbon-containing substance (3). In order to simulate tarnishing in an accelerated immersion test, a tester was designed (3) in which a specimen is attached to a wheel which rotates in the vertical plane in such a manner that the specimen is immersed in a particular solution for part of each revolution. Using this apparatus, the tarnish resistance of two series of gold-silver-copper alloys was evaluated. The first contained 50 atomic per cent gold and varying amounts of silver and copper ( 64 to 76 gold $/ 0$ to 36 silver/0 to 50 copper weight per cent). The second contained 30 to 70 atomic per cent gold (50 to 84 weight per cent) with the ratio of silver to copper set at 1 . After 10 days of immersion in a synthetic saliva solution no tarnish was observed on any of the alloys. However, in a 0.5 per cent solution of sodium sulphide, tarnish developed in almost all the specimens, predominantly at silver-rich regions on the sample surface.

Alloy composition alone does not ensure good tarnish resistance. To demonstrate this, samples of alloys A, B and C (Table I) were placed in a tarnish tester of the model described above and immersed in a 5 per cent sodium sulphide solution for periods of up to 40 days (4). After 9 hours, no discolouration was observed in the Type IV alloy A and the low gold content alloy $\mathrm{C}$; after 2 days, 'pin-point' tarnish regions were visible on alloy $C$; at 6 days the two alloys were readily distinguishable with the naked eye and the intensity of tarnish on alloy $\mathrm{C}$ increased during the rest of the 40-day period. Approximately 27 hours (1 600 revolutions at $1 \mathrm{rpm}$ ) in the test apparatus has been cited as equivalent to 6 months of clinical testing (15). On this basis, it could be predicted that alloy $\mathrm{C}$ would give acceptable clinical performance for periods of up to three years. Of the three compositions evaluated, the sample of 18-carat ternary gold-silver-copper alloy B discoloured fastest and to the greatest extent. Discolouration was noticeable after 1 to 2 hours, and after 2 days the specimen was black. Therefore, not all gold-rich alloys have good tarnish resisitance. Clinical tests on these three alloys confirmed the in vitro results (4). Partial dentures were fabricated containing a button of each alloy and were worn by fifteen patients for six months. Eleven of the buttons of alloy B showed

Tarnish tester based on the design of (3). The vertical wheel, here shown with only one alloy sample in position, is driven by an electric motor so that the specimen is immersed in the test solution during a part of each revolution. The immersion medium could be a synthetic saliva or a more aggressive solution for accelerated tests 
Table I

Compositions of the Dental Gold Alloys Referred to in this Article

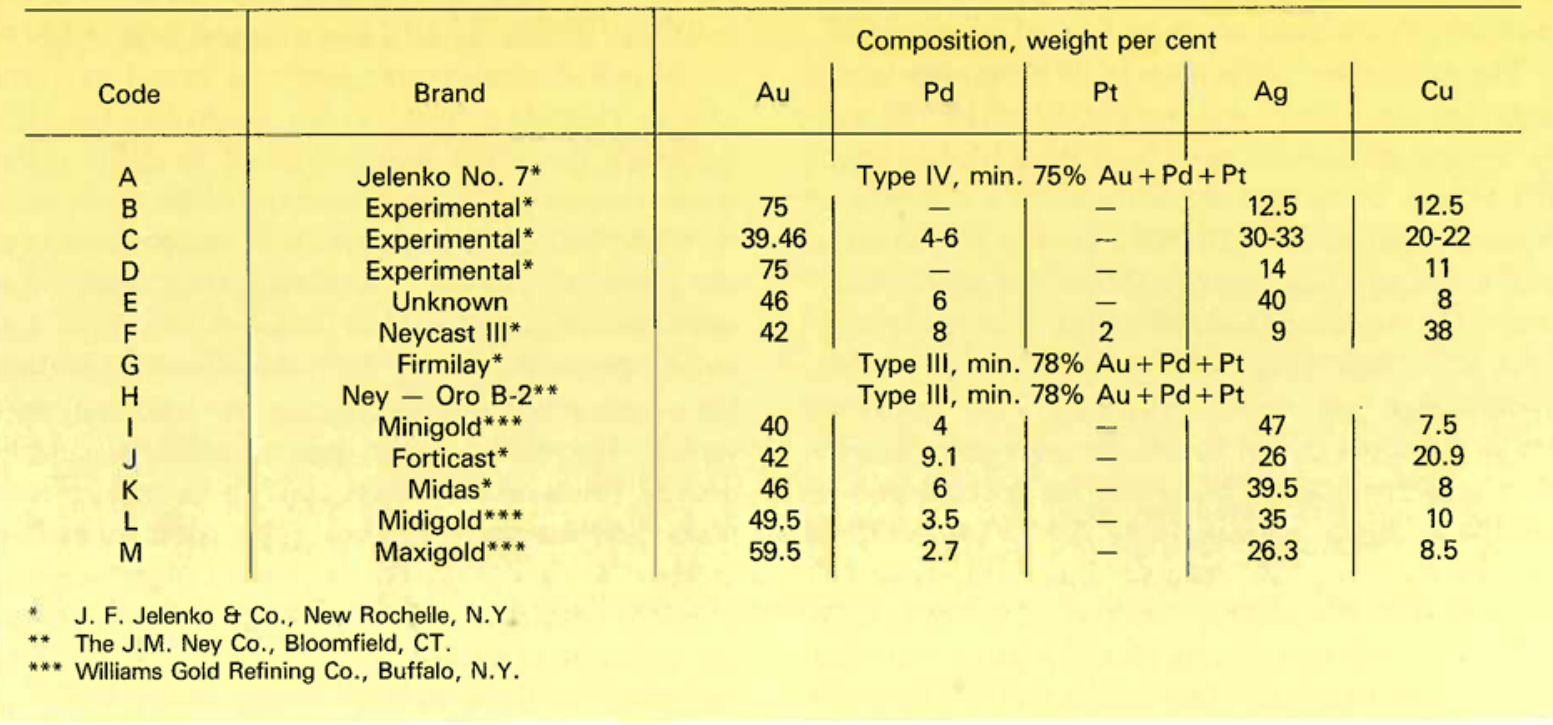

slight to severe tarnish, three of the alloy A buttons showed a slight degree of tarnish and four of the alloy $\mathrm{C}$ buttons tarnished, of which one was rated moderately and another severely discoloured. The tarnish resistance of the Type IV and of the low gold content alloy was not statistically different. Clinical restorations and appliances (220 units) of the Type IV and low gold content alloy were then placed in the mouths of sixty patients. Again, after a six month period, no statistically significant difference was detected in the degree of tarnish or discolouration of alloys $\mathrm{A}$ and $\mathrm{C}$.

Results of later investigations on the alloys $\mathrm{A}$ and $\mathrm{B}$ conflicted with the above. No difference in susceptibility to tarnishing, as determined by colorimetry (16), and corrosion, as measured by a linear polarization technique $(16,17)$, were reported for the Type IV alloy A, the gold-silver-copper alloy B and a sample of pure gold during a 21-day in vitro test period. The investigators suggested that longer time periods or methods having greater sensitivity might be needed to detect differences in behaviour between alloys. More importantly, the inventors of the low gold content alloy C, used in the first study above, later stated (18) that it is susceptible to serious tarnishing in environments containing sulphur.

Poor tarnish resistance was reported (19) for another gold-silver-copper alloy containing 75 per cent gold by weight (D, in Table I). Microprobe analysis for copper, silver and sulphur was performed on the tarnish product which resulted from immersion for one week in a 5 per cent sodium sulphide solution. A silver sulphide compound was detected, but no copper reaction product was observed.
In the development of tarnish-resistant gold alloys, decreasing the gold content necessitates the addition of palladium, while specific silver/copper concentration ratios are maintained (20). Patented (18) low gold content alloys which are claimed to be resistant to sulphide tarnish have the composition (weight per cent): 39 to $47 \mathrm{gold} / 9$ to 12 palladium/balance silver and copper in the concentration ratio of 1 to 1.5 .

Studies by immersion in several media, as well as exposure to sulphide vapours, indicate variability of tarnish resistance with testing environments. After the low gold content alloy E (see Table I) was placed in a 5 per cent sodium sulphide solution at $25^{\circ} \mathrm{C}$ for 13 days, a slight surface dullness was observed (21). A copper specimen was severely corroded after several days under similar test conditions. In chloride environments (Ringer's solution, artificial saliva or $10 \mathrm{per}$ cent ferric chloride $\left(\mathrm{FeCl}_{3} \cdot 6 \mathrm{H}_{2} \mathrm{O}\right)$ ), neither copper nor alloy $\mathrm{E}$ showed any tendency to pitting with immersion times which varied from 3 to 20 days. In these experiments, the tarnish behaviour of test specimens was subjectively evaluated by comparing them against a visual scale.

A tarnish test was developed (22) in which a specimen is exposed to ammonium sulphide vapour and any resultant colour change is assessed by comparision with a set of empirically chosen standards. Both the standard scale and the assignment of a tarnish number to the specimen are subjective.

The tarnished surface regions of clinically placed gold crowns and of cast alloy samples which had been exposed to various solutions which might be found in dental laboratories, have been examined by Auger spectroscopy (23). Elements detected at significant 
levels were: oxygen, chlorine, sulphur, nitrogen, phosphorus, carbon, calcium, magnesium, silicon, aluminium, sodium and tin. This implies that complex tarnish reactions occur in the oral environment.

The evaluation of the degree of tarnishing in the tests described above was mainly subjective. Recently, several procedures have been developed to quantify tarnish using optical instruments: a colorimeter which measures the reflected intensity of particular red, green and blue wavelenghts of the visible spectrum (16); a photocell recording the reflected intensity of white light (15); and a spectrophotometer (24). Colorimeter test results (16) have been described above for alloys A and B, and for pure gold. Several dentists were asked to evaluate visually the degree of tarnishing and surface dullness of low gold content alloys submitted to the rotating wheel accelerated tarnish test (15). The reflected white light intensity from an area of each sample was then compared with that of a control specimen. The results of the subjective evaluations compared well with those of the quantitative technique. Thus, low gold content alloys could be classified according to tarnish resistance. The evaluation by these methods of particular alloy composition is described below.

A spectrophotometer (24) was used to quantify the degree of tarnishing for a series of alloys ranging from gold-copper binaries to complex low gold content formulations. The results showed sulphide tarnish to be dependent on the concentrations of silver and platinum, and on the copper/silver concentration ratio in the alloy. Susceptibility to tarnish is increased by high silver content, but reduced if platinum is present. The conclusion that tarnish mechanisms are complex may be drawn from the observation that the compounds which formed on the sample surface differed with differences in test solutions.

\section{Corrosion}

Corrosion involves a reaction between a material and its environment, resulting in the deterioration of the former. Dental alloys which are placed in the oral environment may be affected by electrochemical corrosion processes. Thus, in vitro corrosion behaviour can be predicted from results of electrochemical testing. Potentiodynamic anodic polarization is an electrochemical technique which charaterizes corrosion behaviour (25) and for low gold content alloys it has been successfully applied to relating resistance to corrosion with composition. In this technique, specimens are scanned through a range of applied potentials, and the current output - which is proportional to the extent of corrosion - is monitored. During forward scanning in the anodic direction, the samples are oxidized; during reverse scanning, they are reduced.
The current-potential relationship for low gold content alloys has been found to exhibit hysteresis when samples are successsively polarized from -200 to $+400 \mathrm{mV}$ during forward scanning and from +400 to $-200 \mathrm{mV}$ during reverse scanning in a 1 per cent sodium chloride solution as the electrolyte $(26,27)$. Although the alloys tested differed in noble metal contents, their corrosion potentials (where the current reverses polarity) and magnitude of current density at any potential, did not differ significantly during forward scanning, that is, their corrosion behaviour was indistinguishable. Also, their breakdown potentials (zero current potentials during reverse scanning) were similar. However, during reverse scanning, current density peaks were observed around $0 \mathrm{mV}$. These peaks were interpreted as being due to the reduction of silver, the major corrodible element in these alloys. A minor contribution to corrosion, stemming from the presence of copper, was recorded. The relative magnitude of these current density peaks, which is proportional to the extent of corrosion, was used to rank the corrosion resistance of the alloys. As the gold + PGM content of dental alloys is decreased, the silver content is normally increased (from 12 to 46 weight per cent, in the alloys discussed here). Corrosion susceptibility, as determined by the relative current density peak magnitudes was found to correlate with the silver content of the alloys studied. Current density peaks of decreasing magnitude were recorded as alloys of decreasing silver content were tested.

A systematic study of binary, ternary and commercial dental gold alloys confirmed that the current density peak at $0 \mathrm{mV}$ during reverse scanning is characteristic of gold alloys containing corrodible silver (28). Binary gold-silver alloys were studied by an electrochemical hysteresis technique similar to that described above. When the silver content of the alloys was decreased from 65 to 15 atomic per cent, the peak observed in the silver-rich alloys was totally suppressed. For binary gold-copper alloys, a current density peak which occurred at $-125 \mathrm{mV}$ during forward scanning, was attributed to the formation of cuprous chloride $(\mathrm{CuCl})$. When gold-silver-copper ternary alloys were examined, current density peaks were found at potentials which indicated that both silver and copper were involved in the corrosion process. The corrosion behaviour of commercial gold alloys having varying noble metal contents was characterized on the basis of current density peaks associated with reactions involving copper and silver. The extent to which a silver-rich second phase was present in these alloys had a secondary effect on their corrosion resistance.

Corrosion-in gold alloys occurs primarily in silverrich regions and secondarily in copper-rich regions (3). Galvanic microcells form on two-phase alloys, 
Table II

Comparison of the Performance of Five Low Gold Dental Alloys during Tarnish, Corrosion and Clinical Tests

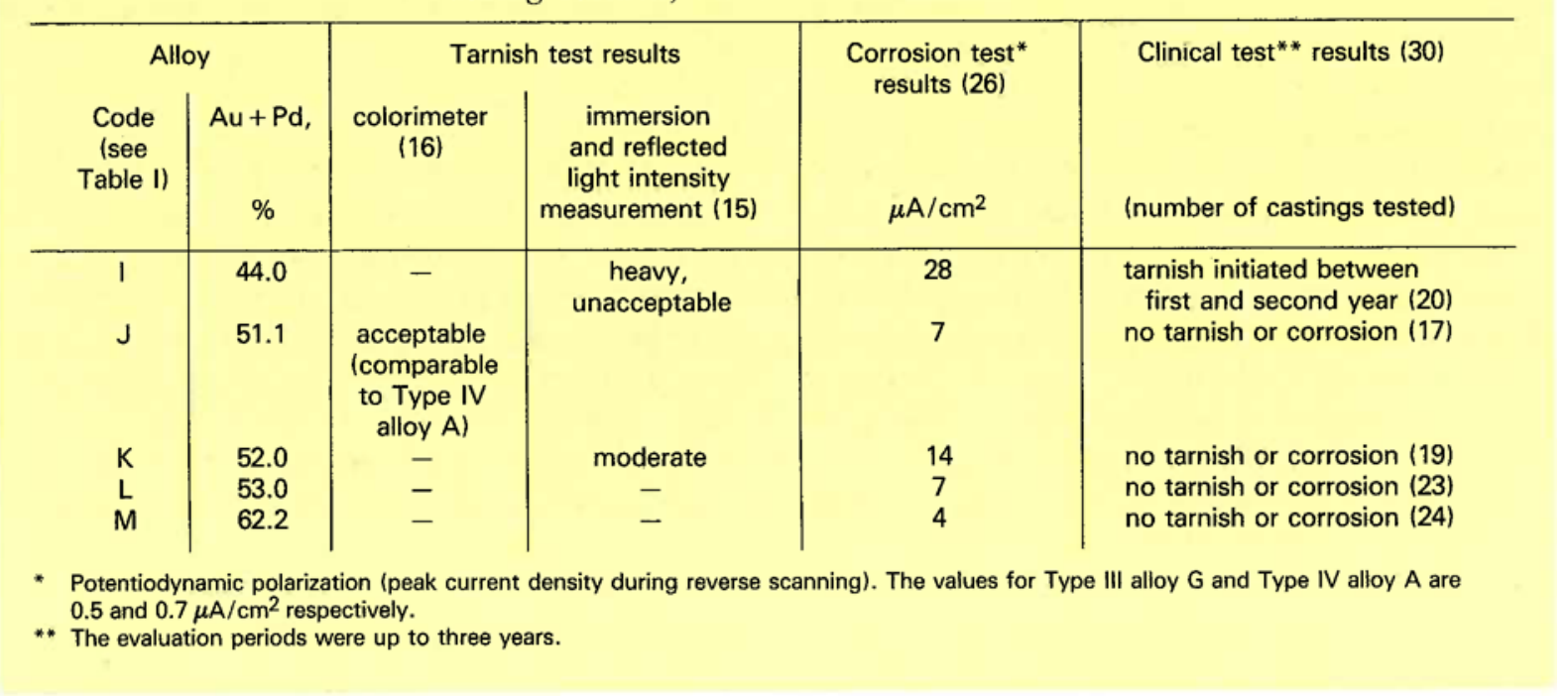

where the more active phase corrodes with respect to the noble matrix. Consequently, the microstructure of an alloy can have an added influence on its corrosion resistance. In a study to examine the effect of casting investment temperature on the microstructure and corrosion characteristics of low gold content dental alloys (29) the rate of cooling was varied by using moulds at 700 and $20^{\circ} \mathrm{C}$. Even rapid cooling resulted in a two-phase structure, but with a fine grain size and a minor proportion of second phase. Potentiodynamic polarization measurements were made on the resulting castings. The magnitudes of the current density peaks; corresponding to copper and silver corrosion processes, were greater for alloys cast into investment at a higher temperature. Therefore, such alloys corroded to a greater extent. These results are indicative of the importance of the microstructure for the corrosion behavior of an alloy, especially of the detrimental effects of a large grain size and of a coarse second phase.

The results of various laboratory methods of testing the tarnish and corrosion of dental alloys correlate well. For instance, the resistance of low gold content alloy $F$ and Type III alloy $G$ (see Table I) to tarnishing by immersion in a sulphide solution was evaluated subjectively by a group of ten dentists, and quantitatively by an optical measurement technique (15). For each alloy, some tarnishing occurred during the initial 6 to 12 months of simulated mouth conditions. During the second year, a small additional amount of tarnish was observed. Both alloys $F$ and $G$ were reported to tarnish to an acceptable level. Electrochemical hysteresis tests conducted on both alloys revealed a current density peak corresponding to silver corrosion that is an order of magnitude larger for the low gold content alloy $F$ than the Type III alloy $\mathrm{G}-6$ against $0.5 \mu \mathrm{A} / \mathrm{cm}^{2}(26)$. A second electrochemical corrosion study (28) of the low gold content alloy $\mathrm{F}$ and the Type III alloy $\mathrm{H}$ indicated comparable current density peak values for the former $-2 \mu \mathrm{A} / \mathrm{cm}^{2}$ for silver corrosion and $1 \mu \mathrm{A} / \mathrm{cm}^{2}$ for copper corrosion. The tarnish and corrosion behaviour of alloy $\mathrm{F}$ compares favourably with that of Type III alloys having long histories of clinical use. Moreover, the above provides evidence that independent test methods lead to a similar conclusion as to tarnish and corrosion resistance of a particular alloy.

\section{Clinical Evaluation}

The value of in vitro tarnish or corrosion tests is restricted to the prediction of clinical behaviour. There is a limited and generally incomplete body of knowledge in the literature concerning the clinical evaluation of low gold content alloys. Five such alloys are described below, for which results of both in vitro tarnish and corrosion tests, and clinical data have been reported. The ability of immersion and electrochemical tests to predict clinical behaviour is examined.

Selected low gold content alloys from Table I are listed in Table II according to increasing noble metal content, ranging from 44 to 62 gold + palladium weight per cent. Alloy $I$ is distinguished from the others by having unacceptably low tarnish resistance. No evidence of tarnish or corrosion was detected during the first year of a clinical evaluation of this alloy (30). However, during the second year of testing, several restorations tarnished at localized areas. One 
case was reported in which tarnish occurred over the entire surface of the restoration; the deposits were identified by means of microprobe analysis as silver sulphide. Visual evaluation and quantitative measurements of the reflected light intensity of specimens of alloy I subjected to immersion tests indicated a heavy tarnish layer, considered to be unacceptable (15). Electrochemical corrosion data have shown a peak value of current density during reverse scanning of $28 \mathrm{uA} / \mathrm{cm}^{2}(26)$, pointing to a reduction process involving silver (31). This value should be compared with the $0.5 \mathrm{uA} / \mathrm{cm}^{2}$ recorded for Type III gold-rich alloy $G$, which is a clinically acceptable alloy. The results of clinical evaluation thus agree with those from tarnish and corrosion laboratory tests.

The clinical evaluations of the remaining four alloys in Table II ( $\mathrm{J}$ to $M$ ) revealed no detectable tarnish or corrosion for periods of up to three years. However, in vitro tests further discriminate among these alloys. Alloy $\mathrm{K}$ develops a moderate amount of tarnish when compared with Type III alloy G (15). Also, the value of peak current density for the silver corrosion process in alloy $\mathrm{K}$ is at least twice as large as for J, $L$ and $M(26)$. Whether these latter observations should be interpreted as predicting detectable tarnish of restorations placed in the oral environment, awaits continuing clinical evaluation. Corrosion (26) and clinical (30) test results obtained independently have confirmed that alloys J, $L$ and $M$ have acceptable corrosion and tarnish resistance; optical testing (16) further supports the view that alloy $\mathrm{J}$ has acceptable tarnish resistance.

\section{Summary}

Today in the U.S.A., approximately two hundred casting alloys containing varying amounts of noble metals are being marketed for dental prostheses. Among the important characteristics of these materials are tarnish and corrosion resistance in the oral environment. Composition restrictions are not sufficient to assure in vivo alloy stability - alloys containing 75 per cent noble metals by weight have been found to tarnish, whereas alloys containing 52 per cent noble metals have not. Furthermore, procedures for screening new alloy formulations prior to marketing have not yet been standardized. State-ofthe-art tarnish and corrosion test methods were discussed, and wherever clinical data were available, the results were compared. For particular alloys there was a good correlation between in vivo and in vitro behaviour. Although further clinical evaluation of low gold content alloys is needed, results to date indicate that specific tarnish and corrosion test methods satisfactorily predict clinical behaviour.

\section{References}

1 W. Souder and G. C. Paffenbarger, 'Physical Propertes of Dental Materials', Circular of the National Bureau of Standards C433, U.S. Gov. Print. Off, 1942, p. 41

2 American National Standards Institute/American Dental Association Specification No. 5 for Dental Casting Gold Alloys, in 'Guide to Dental Materials and Devices', 7th edition, A.D.A., Chicago, IL., 1974, pp. 184-187

3 J. J. Tuccillo and J. P. Nielsen, F. Prosthet. Dent., 1971, 25, 629-637

4 A. B. Burse, M. L. Swartz, R. W. Phillips and R. W. Dykema, f. Biomed. Mater. Res., 1972, 6, 267-277

5 R. W. Bauer, Natl. Assoc. Dent. Lab. F., 1977, 24, (3), 7-11

6 Council of Dental Materials, Instruments, and Equipment, 7. Am. Dent. Assoc., 1980, 100, 237-240

7 L. H. Lofstrom, G. E. Meyers and K. Asgar, in 'IADR Program and Abstracts of Papers', Paper No. 137, 7. Dent. Res., $1976, \mathbf{5 5 B}, \mathrm{B} 96$

8 W. S. Howard, S. M. Newman and L. J. Nunez, f. Dent. Res., 1980, 59, 824-830

9 D. A. Nitkin and K. Asgar, f. Am. Dent. Assoc., 1976, 93 622-629

10 C. M. Sturdevant, K. F. Leinfelder and R. P. Kusy, in 'IADR Program and Abstracts of Papers', Paper No. 415, 7. Dent. Res., 1979, 58A, 197

11 J. M. Gourley, f. Can. Dent. Assoc., 1975, 41, 453-455

12 K. F.Leinfelder, W. J. O'Brien and D. F. Taylor, f. Dent. Res., 1972, 51, 900-905

13 Council on Dental Materials and Devices, F. Am. Dent. Assoc., $1976, \mathbf{9 3}, 1188-1189$

14 M. L. Swartz. R. W. Phillips and M. D. E1 Tannir, f. Dent. Res., 1958, 37, 837-847

15 R. P. Lubovich, R. E. Kovarik and D. L. Kinser, F. Prosthet. Dent., 1979, 42, 534-538

16 L. Gettleman, C. Amman and N. K. Sarkar, in 'IADR Program and Abstracts of Papers', Paper No. 969, 7. Dent. Res., $1979, \mathbf{5 8 A}, 334$

17 L. Gettleman, F. H. Cocks, L. A. Darmiento, P. A. Levine, S. Wright and D. Nathanson, f. Dent. Res., 1980, 59, 689-707
18 J. J. Tuccillo and J. P. Nielsen, U.S. Patent 3,767,391 (1973) 19 J. J. Tuccillo and J. P. Nielsen, f. Prosthet. Dent., 1974, 31, 285-289

20 J. J. Tuccillo, in 'Alternatives to Gold Alloys in Dentistry', edited by T. M. Valega, U.S. Department of Health, Education and Welfare Publ. No. (NIH) 77-1227, Washington, D.C., 1977 , pp. 40-67

21 R. J. Hodges, in 'Alternatives to Gold Alloys in Dentistry', edited by T. M. Valega, U.S. DHEW Publ. No. (NIH) 77-1227, Washington, D.C., 1977, pp. 106-138

22 C. Ingersoll, in 'IADR Program and Abstracts of Papers', Paper No. 467, F. Dent. Res., 1975, 54A, 162

23 C. Ingersoll, in 'IADR Program and Abstracts of Papers', Paper No. 144, f. Dent. Res., 1976, 55B, B97

24 R. M. German, Paper presented at the International Precious Metals Institute Meeting, Chicago, IL., 1979

25 ASTM Committee G-1 on Corrosion of Metals, 'G5-Standard Recommended Practice for Standard Reference Method for Making Potentiostatic and Potentiodynamic Anodic Polarization Measurements', Am. Soc. Test. Mater., Philadelphia, PA., 1971

26 N. K. Sarkar, R. A. Fuys, Jr. and J. W. Stanford, F. Dent. Res., $1979, \mathbf{5 8}, 568-575$

27 N. K. Sarkar, R. A. Fuys, Jr. and J. W. Stanford, in 'Corrosion and Degradation of Implant Materials', edited by B. C. Syrett and A. Acharya, ASTM Spec. Tech. Publ. 684, Am. Soc. Test. Mater. Philadelphia, PA., pp. 277-293

28 D. C. Wright, R. M. German and R. F, Gallant, in 'AADR Program and Abstracts of Papers', Paper No. 1027, f. Dent. Res., 1980, 59A, 526

29 R. F. Gallant, R. M. German and D. C. Wright, in 'AADR Program and Abstracts of Papers', Paper No. 1030, f. Dent. Res., 1980, 59A, 526

30 C. M. Sturdevant and K. F. Leinfelder, in 'AADR Program and Abstracts of Papers', Paper No. 819, F. Dent. Res., 1980 59A, 472

31 N. K. Sarkar, in 'AADR Program and Abstracts of Papers', Paper No. 1026, f. Dent. Res., 1980, 59A, 525 